Article

\title{
Improving the Performance of ZnS Photocatalyst in Degrading Organic Pollutants by Constructing Composites with $\mathrm{Ag}_{2} \mathrm{O}$
}

\author{
Dequan Yu ${ }^{1}$, Hao Fang ${ }^{1, *}$, Peikai Qiu ${ }^{1}$, Fancong Meng ${ }^{1}$, Haixia Liu ${ }^{1, *} \mathbb{D}$, Shuai Wang ${ }^{1, *} \mathbb{C}$, Pingli Lv ${ }^{2}$, \\ Xiaoyan Cong ${ }^{3}$, Qingfen $\mathrm{Niu}^{1}$ and Tianduo $\mathrm{Li}^{1, *}$ \\ 1 School of Chemistry and Chemical Engineering, Shandong Provincial Key Laboratory of Molecular \\ Engineering, Qilu University of Technology, Jinan 250353, China; dequanyu_qlu@hotmail.com (D.Y.); \\ peikaiqiu@hotmail.com (P.Q.); mengfancong2021@hotmail.com (F.M.); qfnchemqlu@hotmail.com (Q.N.) \\ 2 School of Light Industry Science and Engineering, Qilu University of Technology, Jinan 250353, China; \\ qlgdlpl@163.com \\ 3 Jinan Kuoda Biological Technology CO., LTD, Jinan 250107, China; congxiaoyankuoda@hotmail.com \\ * Correspondence: unifht@163.com (H.F.); liuhaixia929@163.com (H.L.); qkwangshuai@163.com (S.W.); \\ litianduo@163.com (T.L.)
}

Citation: Yu, D.; Fang, H.; Qiu, P.; Meng, F.; Liu, H.; Wang, S.; Lv, P.; Cong, X.; Niu, Q.; Li, T. Improving the Performance of ZnS Photocatalyst in Degrading Organic Pollutants by Constructing Composites with $\mathrm{Ag}_{2} \mathrm{O}$. Nanomaterials 2021, 11, 1451. https:// doi.org/10.3390/nano11061451

Academic Editors: Michael Arkas; Ioannis Pashalidis; Dimitrios

A. Giannakoudakis and

Ioannis Anastopoulos

Received: 29 April 2021

Accepted: 27 May 2021

Published: 30 May 2021

Publisher's Note: MDPI stays neutral with regard to jurisdictional claims in published maps and institutional affiliations.

Copyright: (c) 2021 by the authors. Licensee MDPI, Basel, Switzerland. This article is an open access article distributed under the terms and conditions of the Creative Commons Attribution (CC BY) license (https:// creativecommons.org/licenses/by/ $4.0 /)$.

\begin{abstract}
ZnS is a promising photocatalyst in water purification, whereas its low photon efficiency and poor visible-light response restrict its application. Constructing composites may help solve these problems. In this work, $\mathrm{Ag}_{2} \mathrm{O}$ was introduced to $\mathrm{ZnS}$ for the first time based on their energy band characteristics to form a novel $\mathrm{ZnS} / \mathrm{Ag}_{2} \mathrm{O}$ composite photocatalyst. In the model reaction of degrading methylene blue, the as-designed catalyst exhibited high catalytic activity among a series of ZnS-based composite photocatalysts under similar conditions. The catalytic rate constant was up to $0.138 \mathrm{~min}^{-1}$, which is 27.4- and 15.6-times higher than those of $\mathrm{ZnS}$ and $\mathrm{Ag}_{2} \mathrm{O}$. This composite degraded $92.4 \%$ methylene blue in $50 \mathrm{~min}$, while the ratios were $31.9 \%$ and $68.8 \%$ for $\mathrm{ZnS}$ and $\mathrm{Ag}_{2} \mathrm{O}$. Catalytic mechanism study based on photoluminescence and radical-scavenging experiments revealed that the enhanced photocatalytic activity was attributed to the composite structure of $\mathrm{ZnS} / \mathrm{Ag}_{2} \mathrm{O}$. The structure not only facilitated the separation and transmission of photogenerated carriers but also extended the light response range of the catalyst. The as-designed $\mathrm{ZnS} / \mathrm{Ag}_{2} \mathrm{O}$ composite is promising in degrading organic pollutants in water.
\end{abstract}

Keywords: water treatment; composite materials; nanomaterials; photocatalysis; organic pollutants

\section{Introduction}

Zinc sulfide (ZnS) is a promising photocatalyst which has broad applications in environmental fields, especially degrading organic pollutants and water purification [1-8]. As a typical n-type semiconductor, $\mathrm{ZnS}$ has received increasing attention, owing to its more negative reduction potential under irradiation [9-12]. However, improving its catalytic activity is hindered by two challenges: Poor visible-light response for its wide band gap [13] and low photon efficiency for its rapid electron-hole recombination [14]. To solve these problems, many strategies have been explored [15-19]. Among them, combining different types of semiconductors to form composites can improve the transmitting efficiency of photogenerated carriers and extend the spectral response range [20-23]. Therefore, compositing appropriate semiconductors is an effective approach to enhance the photocatalytic activity of ZnS.

Silver oxide $\left(\mathrm{Ag}_{2} \mathrm{O}\right)$, a p-type semiconductor with a narrow band gap, has been widely used as an antibacterial material, colorant, preservative, and electrode material [24-27]. It has also been a promising photocatalyst since Wang et al. [28,29] discovered its photocatalytic activity. Subsequently, a series of $\mathrm{Ag}_{2} \mathrm{O}$-involved composites have been reported, such as $\mathrm{TiO}_{2} / \mathrm{Ag}_{2} \mathrm{O}$ [30], $\mathrm{ZnO} / \mathrm{Ag}_{2} \mathrm{O}$ [31], $\mathrm{Bi}_{2} \mathrm{WO}_{6} / \mathrm{Ag}_{2} \mathrm{O}$ [32], and $\mathrm{g}-\mathrm{C}_{3} \mathrm{~N}_{4} / \mathrm{Ag}_{2} \mathrm{O}$ [33]. Benefitting from the efficient carrier separation of composites and extended light response 
range due to the narrow band gap of $\mathrm{Ag}_{2} \mathrm{O}$, these composites display higher photocatalytic activities than respective components. Therefore, combining n-type semiconductor $\mathrm{ZnS}$ with p-type semiconductor $\mathrm{Ag}_{2} \mathrm{O}$ to form a composite may elevate the activity of pristine $\mathrm{ZnS}$.

Herein, $\mathrm{Ag}_{2} \mathrm{O}$ was introduced to $\mathrm{ZnS}$ for the first time based on respective energy band characteristics. A novel $\mathrm{ZnS} / \mathrm{Ag}_{2} \mathrm{O}$ photocatalyst was constructed and synthesized by a simple chemical precipitation method. The as-designed photocatalyst was composed of n-type semiconductor $\mathrm{ZnS}$ and p-type semiconductor $\mathrm{Ag}_{2} \mathrm{O}$, exhibiting higher catalytic activities than pristine $\mathrm{ZnS}$ or $\mathrm{Ag}_{2} \mathrm{O}$ toward degrading the model pollutant methylene blue (MB). Furthermore, the composite exhibited a high-rate constant of $0.138 \mathrm{~min}^{-1}$, indicating a high catalytic activity among a series of ZnS-based photocatalysts under similar conditions. Catalysis mechanism study of the enhanced activity revealed that the $\mathrm{ZnS} / \mathrm{Ag}_{2} \mathrm{O}$ composite not only facilitated the separation and transmission of photoelectrons and holes but also extended the light response range of the photocatalyst. The as-designed $\mathrm{ZnS} / \mathrm{Ag}_{2} \mathrm{O}$ composite is a promising photocatalyst for degrading hazardous organic pollutants in the water purification application.

\section{Materials and Methods}

\subsection{Chemicals}

Zinc nitrate hexahydrate $\left(\mathrm{Zn}\left(\mathrm{NO}_{3}\right)_{2} \cdot 6 \mathrm{H}_{2} \mathrm{O}\right.$, A.R.), thiourea $\left(\mathrm{CH}_{4} \mathrm{~N}_{2} \mathrm{~S}\right.$, A.R.), polyvinylpyrrolidone (PVP, A.R.), and sodium hydroxide ( $\mathrm{NaOH}$, A.R.) were purchased from Sinopharm Chemical Reagent Co., Ltd. (SCRC, Beijing, China). Silver nitrate $\left(\mathrm{AgNO}_{3}\right.$, A.R.) was supplied by Sigma Aldrich (Merck KGaA, Darmstadt, Germany). All chemicals were used without further purification. Aqueous solutions were prepared using deionized water.

\subsection{Synthesis of ZnS Broccoli-Like Microspheres}

$\mathrm{ZnS}$ broccoli-like microspheres were synthesized through the hydrothermal process. In a typical process, a certain amount of $\mathrm{Zn}\left(\mathrm{NO}_{3}\right)_{2}(0.1 \mathrm{M}), \mathrm{CH}_{4} \mathrm{~N}_{2} \mathrm{~S}(0.3 \mathrm{M})$, and $0.05 \mathrm{~g}$ PVP were mixed together, and stirred for $30 \mathrm{~min}$. The suspension was transferred into a Teflon-lined autoclave and kept at $120{ }^{\circ} \mathrm{C}$ for $12 \mathrm{~h}$. The final products were collected by centrifugation, washed with ethanol, and deionized water for several times. Then, the products were dried in an oven at $60^{\circ} \mathrm{C}$ for $6 \mathrm{~h}$. The products obtained under other temperatures were synthesized under corresponding temperatures while keeping other conditions consistent.

\subsection{Synthesis of $\mathrm{ZnS} / \mathrm{Ag}_{2} \mathrm{O}$ Composite}

In a typical process, $0.2 \mathrm{~g}$ as-prepared $\mathrm{ZnS}$ was dispersed in $50 \mathrm{~mL}$ deionized water, and $0.117 \mathrm{~g} \mathrm{AgNO}_{3}$ was added to the suspension. After vigorous stirring for $30 \mathrm{~min}$, a certain amount of $2 \mathrm{M} \mathrm{NaOH}$ was added dropwise to the suspension until it reached a $\mathrm{pH}$ of 14 . Then, the composite was collected by centrifuging at $5000 \mathrm{rpm}$. The composite was then washed with deionized water and dried at $60^{\circ} \mathrm{C}$. In addition, the pristine $\mathrm{Ag}_{2} \mathrm{O}$ was synthesized through a similar approach at room temperature, which was used as a contrast sample.

\subsection{Characterizations of Samples}

The crystallographic phases of samples were characterized by X-ray diffraction (XRD) using a Bruker D8 Advance X-ray powder diffractometer (Bruker Corp., Billerica, MA, USA) with $\mathrm{Cu}-\mathrm{K} \alpha$ radiation $(\lambda=1.5418 \AA$ ). Morphological observations were performed by a Hitachi S-4800 field emission scanning electron microscope (SEM, Tokyo, Japan). The diffuse reflectance spectra (DRS) were recorded by a Shimadzu UV-2600 spectrophotometer equipped with an integrating sphere, using $\mathrm{BaSO}_{4}$ as the reflectance standard. Photoluminescence (PL) spectra were obtained by an Edinburgh FLS920 fluorescence spectrom- 
eter (Edinburgh Instruments Ltd., Livingston, England) under an excitation wavelength of $325 \mathrm{~nm}$.

\subsection{Photocatalytic Activity Tests}

The photocatalytic activities of the as-prepared samples were evaluated in terms of the model reaction of degrading MB. The $300 \mathrm{~W}$ xenon lamp (PLS-SXE300UV, Perfectlight Co., Ltd., Beijing, China) was positioned $10 \mathrm{~cm}$ away from the cuvette and was used as light source to trigger the photocatalytic reaction. In a typical test, $0.05 \mathrm{~g}$ of a certain sample was dispersed into $100 \mathrm{~mL} \mathrm{MB}$ solution $(10 \mathrm{mg} / \mathrm{L})$ with magnetic stirring. The suspension was stirred constantly in the dark for $1 \mathrm{~h}$ to achieve the absorption equilibrium before irradiation. The residual concentration of MB was determined by UV-2600 UV-Vis spectroscopy (Shimadzu, Kyoto, Japan).

\section{Results and Discussion}

Figure 1 shows the XRD patterns of the as-prepared $\mathrm{ZnS}, \mathrm{Ag}_{2} \mathrm{O}$, and $\mathrm{ZnS} / \mathrm{Ag}_{2} \mathrm{O}$ composite. From the XRD pattern in black, it is evident that all the diffraction peaks can be well-indexed to the hexagonal wurtzite structure of ZnS (JCPDS 80-0007), with characteristic diffractions of the (100), (002), (101), (110), (103), and (112) crystal planes. The pattern in red can be assigned to the $\mathrm{Ag}_{2} \mathrm{O}$ in cubic phase (JCPDS 43-0997). The typical peaks in good crystallinity of $\mathrm{Ag}_{2} \mathrm{O}$ can be clearly identified as (111), (200), (220), and (311) facets. For the $\mathrm{ZnS} / \mathrm{Ag}_{2} \mathrm{O}$ composite, the XRD pattern is composed of two sets of characteristic peaks, which are the hexagonal $\mathrm{ZnS}$ and cubic $\mathrm{Ag}_{2} \mathrm{O}$ phase. In addition, there is no characteristic peak relevant to another phase, which demonstrates the high purity of the product. Therefore, the as-prepared typical sample is indeed a composite composed of $\mathrm{ZnS}$ and $\mathrm{Ag}_{2} \mathrm{O}$.

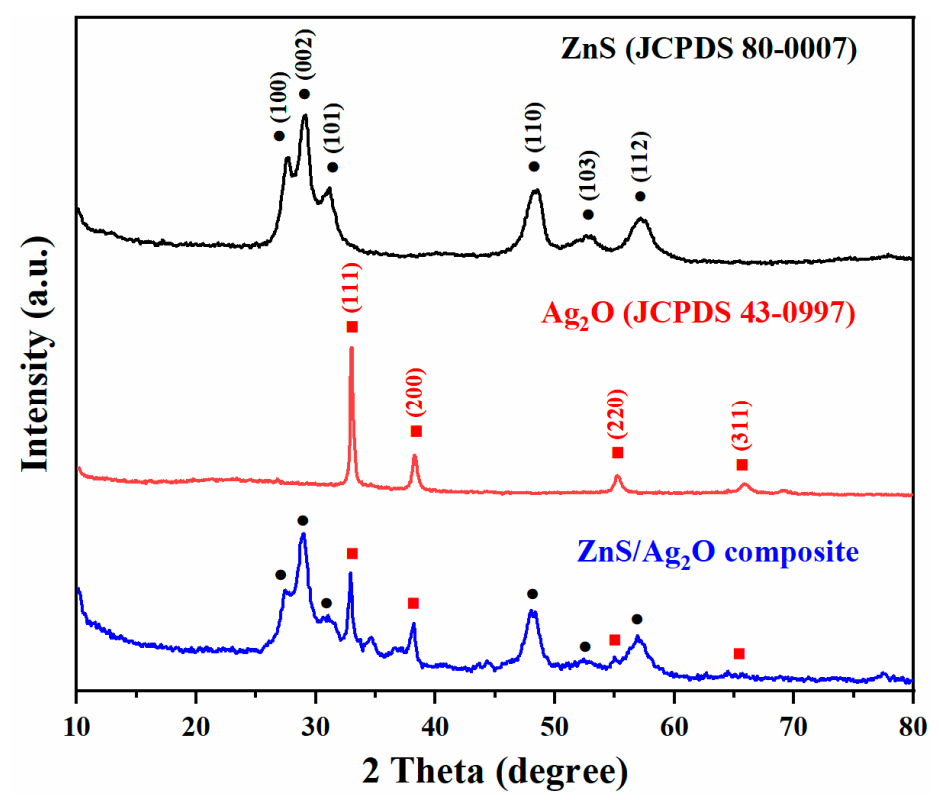

Figure 1. XRD patterns of the as-prepared $\mathrm{ZnS}, \mathrm{Ag}_{2} \mathrm{O}$, and $\mathrm{ZnS} / \mathrm{Ag}_{2} \mathrm{O}$ composite. Standard XRD peaks of $\mathrm{ZnS}$ (JCPDS 80-0007) and $\mathrm{Ag}_{2} \mathrm{O}$ (JCPDS 43-0997) are marked.

The details of morphology and microstructure of as-prepared $\mathrm{ZnS}, \mathrm{Ag}_{2} \mathrm{O}$, and $\mathrm{ZnS} / \mathrm{Ag}_{2} \mathrm{O}$ composite were studied by SEM. Figure $2 \mathrm{a}, \mathrm{b}$ show the typical images of pristine $\mathrm{ZnS}$ at different magnifications. As-prepared $\mathrm{ZnS}$ are shown as broccoli-like microspheres with an average size around 3-4 $\mu \mathrm{m}$. Moreover, the microspheres had rough surfaces, providing a plenty of sites for $\mathrm{Ag}_{2} \mathrm{O}$ to nucleate and grow and facilitating the formation of the $\mathrm{ZnS} / \mathrm{Ag}_{2} \mathrm{O}$ composite. Figure $2 \mathrm{c}$ displays an SEM image of pristine $\mathrm{Ag}_{2} \mathrm{O}$ which has a morphology with irregular aggregation of lots of nanoparticles with a diameter about 
200-300 nm. Figure 2d,e exhibit the morphology of $\mathrm{ZnS} / \mathrm{Ag}_{2} \mathrm{O}$ composite at different magnifications. The morphology of $\mathrm{ZnS}$ was not affected and still maintained the original broccoli-like microspheres after composition with $\mathrm{Ag}_{2} \mathrm{O}$. The $\mathrm{Ag}_{2} \mathrm{O}$ nanoparticles were uniformly covered on the surface of $\mathrm{ZnS}$ microspheres, constituting the $\mathrm{ZnS} / \mathrm{Ag}_{2} \mathrm{O}$ composite. In addition, EDX spectrum of $\mathrm{ZnS} / \mathrm{Ag}_{2} \mathrm{O}$ composite was acquired simultaneously with SEM, as displayed in Figure 2f. The characteristic X-ray peaks of $\mathrm{Zn}, \mathrm{Ag}, \mathrm{S}$, and $\mathrm{O}$ can be found without other element emerges, revealing the elemental composition of the composite.

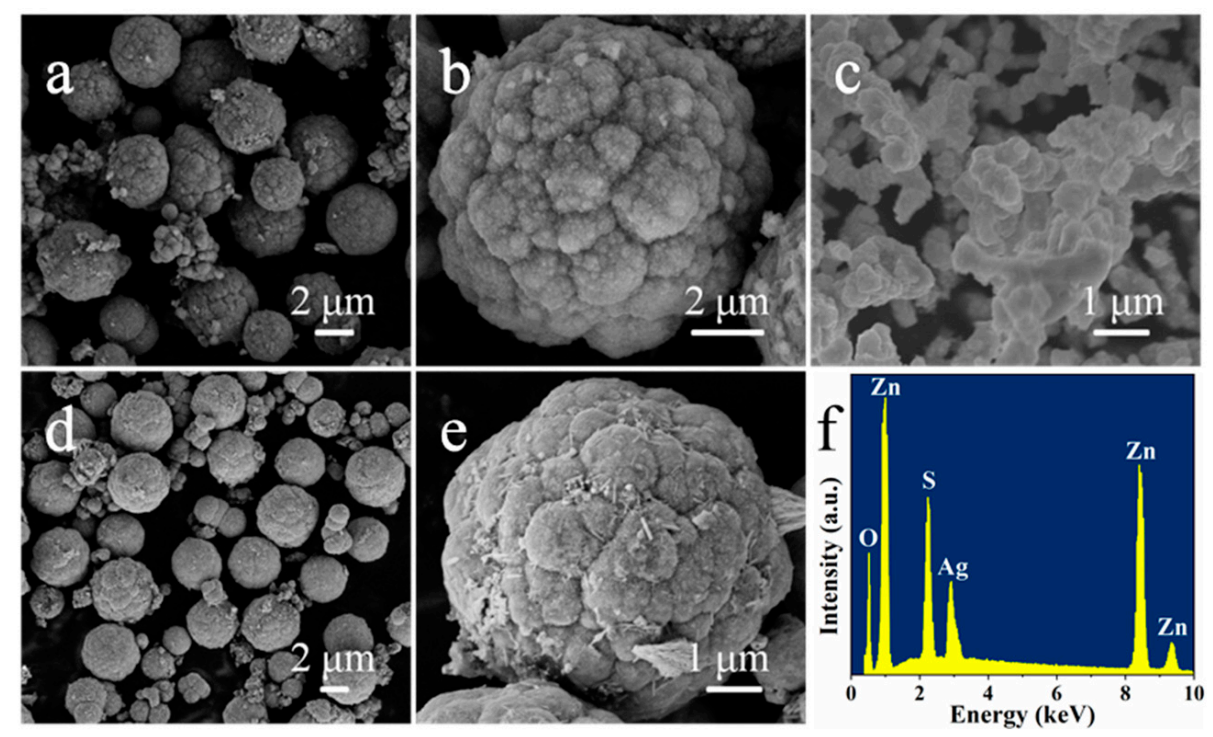

Figure 2. (a,b) SEM images of $\mathrm{ZnS}$ at different magnifications, (c) SEM image of $\mathrm{Ag}_{2} \mathrm{O}$, (d,e) SEM images of $\mathrm{ZnS} / \mathrm{Ag}_{2} \mathrm{O}$ composite at different magnifications, (f) EDX spectrum of $\mathrm{ZnS} / \mathrm{Ag}_{2} \mathrm{O}$ composite.

To explore the law of morphology evolution, condition control experiments on morphologies were carried out. Among these influencing factors, temperature showed more obvious regularity. Figure 3 a displays the $\mathrm{ZnS}$ microspheres obtained at a temperature of $90^{\circ} \mathrm{C}$ while the other experiment conditions were kept identical to the typical sample $\left(120^{\circ} \mathrm{C}\right)$. The as-obtained product was mainly $\mathrm{ZnS}$ microspheres with plenty of nanoparticles. The diameter of the microspheres was around $3 \mu \mathrm{m}$. As the temperature increased to $150{ }^{\circ} \mathrm{C}$ (Figure $3 \mathrm{~b}$ ), the morphology of the product did not change significantly, remaining spherical. However, the proportion of $\mathrm{ZnS}$ microspheres decreased while that of the nanoparticles increased. Besides, the diameter of $\mathrm{ZnS}$ microspheres became uneven. In Figure $3 c$, at a temperature of $200{ }^{\circ} \mathrm{C}$, there were no separate $\mathrm{ZnS}$ microspheres in the product. Agglomerates emerged that were composed of $\mathrm{ZnS}$ microspheres, and the shape of the $\mathrm{ZnS}$ microspheres became blurred and uneven in size.
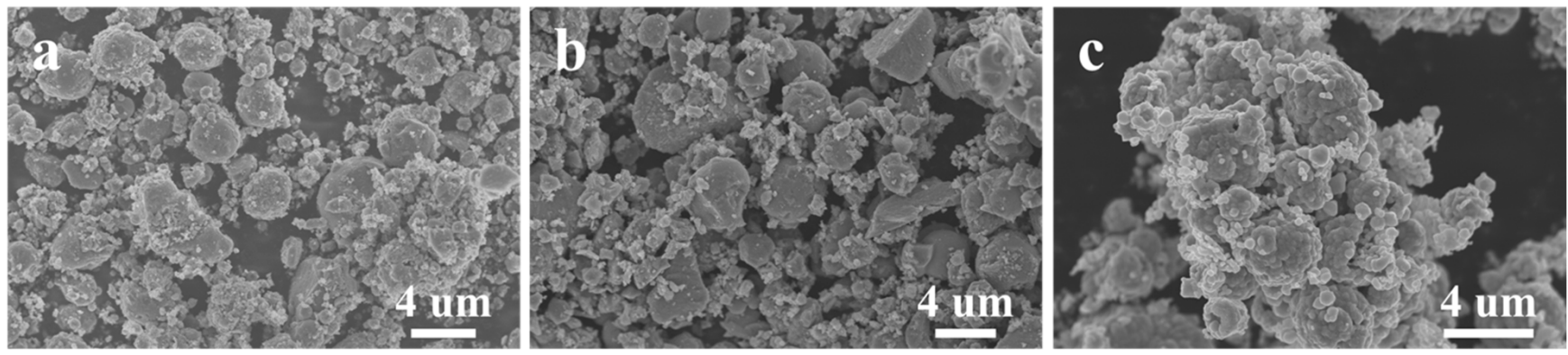

Figure 3. SEM images of ZnS obtained at different temperatures: (a) $90^{\circ} \mathrm{C}$, (b) $150{ }^{\circ} \mathrm{C}$, (c) $200^{\circ} \mathrm{C}$. 
To investigate whether the introduction of $\mathrm{Ag}_{2} \mathrm{O}$ improved the light absorption properties of ZnS, UV-Vis DRS and derived Tauc plots were acquired to obtain the band gap energy for the $\mathrm{ZnS}, \mathrm{Ag}_{2} \mathrm{O}$, and $\mathrm{ZnS} / \mathrm{Ag}_{2} \mathrm{O}$ composite. As-obtained plots are shown in Figure $4 \mathrm{a}$. The absorption edge of pristine $\mathrm{ZnS}$ was around $340 \mathrm{~nm}$ in the UV region, while the pristine $\mathrm{Ag}_{2} \mathrm{O}$ exhibited strong light absorption performance both in the UV and visible light regions, which is ascribed to its much lower energy for band gap transition. Combining the light absorption properties of $\mathrm{ZnS}$ and $\mathrm{Ag}_{2} \mathrm{O}$ in $\mathrm{UV}$ and visible light regions of 300-800 nm, the $\mathrm{ZnS} / \mathrm{Ag}_{2} \mathrm{O}$ composite achieved a great elevation in light absorption in visible light regions, forming an obvious contrast to pristine $\mathrm{ZnS}$. Figure $4 \mathrm{~b}$ shows the Tauc plot of the three samples. The band gap energy of semiconductors can be obtained from the $x$-axis intercept of the extended line. From the graph, the band gap energy values for the $\mathrm{ZnS}, \mathrm{Ag}_{2} \mathrm{O}$, and $\mathrm{ZnS} / \mathrm{Ag}_{2} \mathrm{O}$ composite were determined to be $3.52 \mathrm{eV}, 1.80 \mathrm{eV}$ and $2.85 \mathrm{eV}$, respectively, which suggests that the band gap energy of $\mathrm{ZnS}$ was greatly reduced after introducing $\mathrm{Ag}_{2} \mathrm{O}$ to $\mathrm{ZnS}$ to form the composite. In particular, the band gap energy changed from $3.52 \mathrm{eV}$ to $2.85 \mathrm{eV}$. The results demonstrate huge improvement by the introduction of $\mathrm{Ag}_{2} \mathrm{O}$, which led to a higher photon efficiency and extended the light response range of the composite.

a

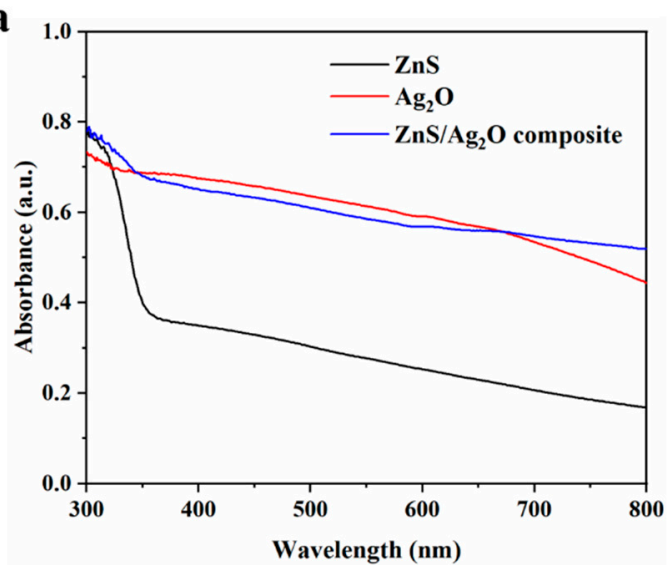

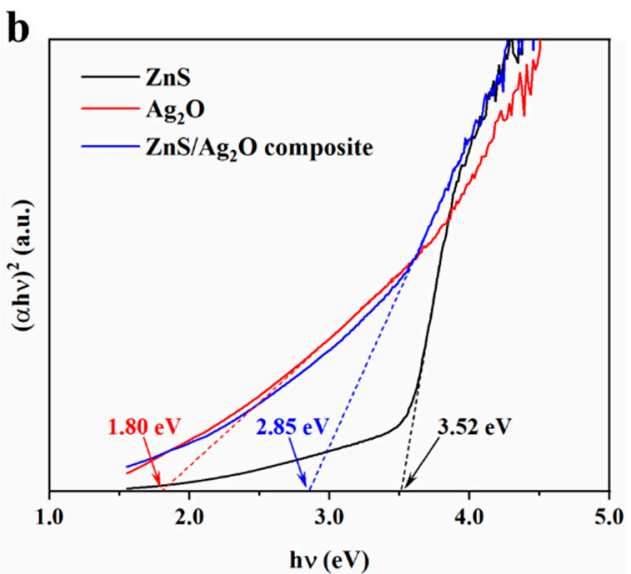

Figure 4. (a) UV-Vis DRS spectra and (b) Tauc plots of $\mathrm{ZnS}, \mathrm{Ag}_{2} \mathrm{O}$, and $\mathrm{ZnS} / \mathrm{Ag}_{2} \mathrm{O}$ composite to show their band gap energy values.

For photocatalysts, PL spectrum is crucial because it is related to the recombination of photogenerated electrons and holes. High fluorescence intensity means that there will be less carriers involved in the photocatalytic reaction, resulting in a low quantum efficiency of catalysts. Under the exciting wavelength of $325 \mathrm{~nm}$, PL spectra of pristine $\mathrm{ZnS}$ and $\mathrm{ZnS} / \mathrm{Ag}_{2} \mathrm{O}$ composite were obtained, as shown in Figure 5. The $\mathrm{ZnS}$ showed two strong emission peaks at $423 \mathrm{~nm}$ and $472 \mathrm{~nm}$. For semiconductors, two emission peaks were observed, corresponding to interstitial and trapped surface state emission, respectively. The emission peak at $423 \mathrm{~nm}$ is evidence of sulfur vacancies due to the recombination of electrons from shallow trap state to the sulfur vacancies, which is consistent with the results reported previously [34]. The emission peak centered at $472 \mathrm{~nm}$ can be attributed to the zinc vacancies in $\mathrm{ZnS}$ lattice. After the addition of $\mathrm{Ag}_{2} \mathrm{O}$, the fluorescence intensities of $\mathrm{ZnS} / \mathrm{Ag}_{2} \mathrm{O}$ composite decreased greatly, indicating that photogenerated electrons and holes can rapidly migrate between $\mathrm{ZnS}$ and $\mathrm{Ag}_{2} \mathrm{O}$, thus suppressing the recombination of carriers. 


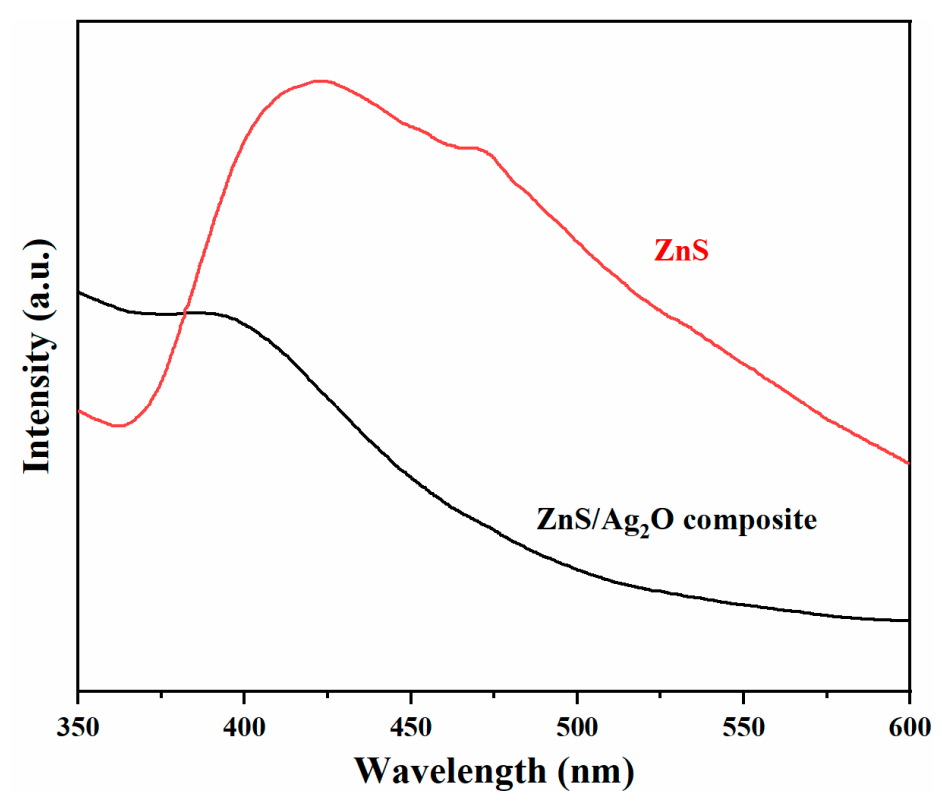

Figure 5. PL spectra of $\mathrm{ZnS}$ and $\mathrm{ZnS} / \mathrm{Ag}_{2} \mathrm{O}$ composite.

The photocatalytic activity of obtained $\mathrm{ZnS} / \mathrm{Ag}_{2} \mathrm{O}$ composite was evaluated by the model reaction of degrading $\mathrm{MB}$ under UV-Vis irradiation. For comparison, tests of $\mathrm{ZnS}$ and $\mathrm{Ag}_{2} \mathrm{O}$ were also conducted under the same condition. Before irradiation, the solution of MB was stirred evenly with certain catalyst in the dark for $60 \mathrm{~min}$ to achieve the absorptiondesorption equilibrium. The original UV-Vis spectra data of the three typical samples recorded at different time during the tests are plotted in Figure 6. The data exhibit the overlapped UV-Vis absorption spectra with a major peak at $664 \mathrm{~nm}$, which indexed to the characteristic absorption peak of MB. In Figure 6a, the peak of MB decreased slowly and was catalyzed by $\mathrm{ZnS}$, and the MB was degraded $31.9 \%$ in $50 \mathrm{~min}$. However, as shown in Figure $6 \mathrm{~b}$, the $\mathrm{Ag}_{2} \mathrm{O}$ catalyst showed a faster degradation rate than $\mathrm{ZnS}$. The peak at 664 $\mathrm{nm}$ decreased by $68.8 \%$ within the same time, whereas the $\mathrm{ZnS} / \mathrm{Ag}_{2} \mathrm{O}$ composite exhibited the highest activity. The concentration of $\mathrm{MB}$ decreased rapidly, and $92.4 \%$ of $\mathrm{MB}$ was degraded in $50 \mathrm{~min}$. The results demonstrate that the $\mathrm{ZnS} / \mathrm{Ag}_{2} \mathrm{O}$ composite had a better performance than both of its components. The superior performance of the photocatalyst can be attributed to the improved visual light response of the composite and its higher photon efficiency.
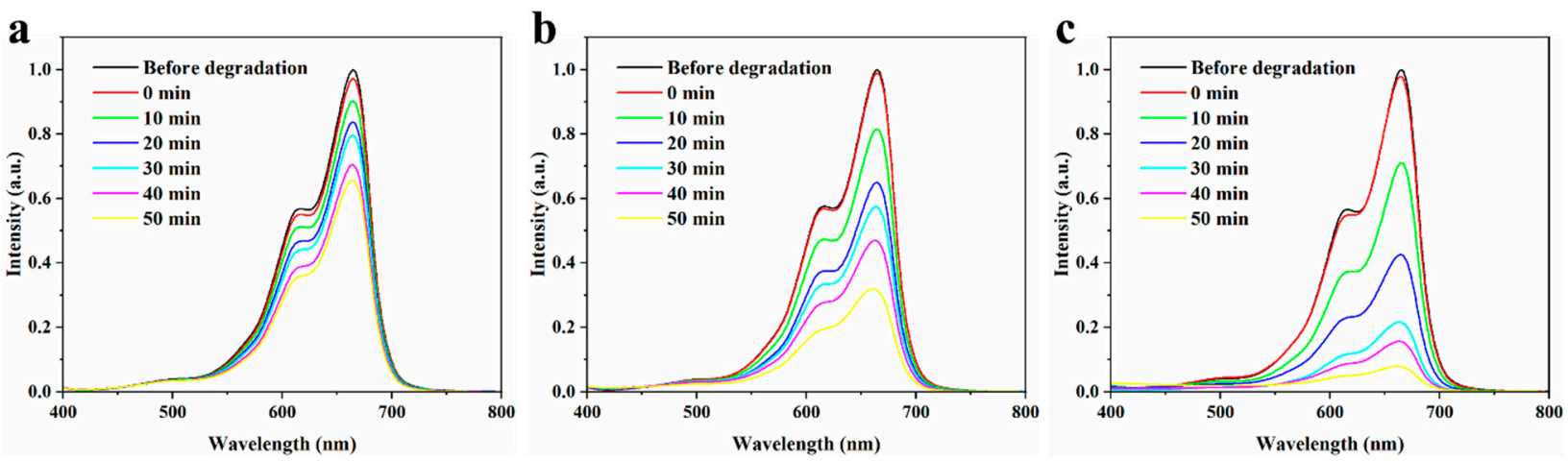

Figure 6. UV-Vis absorption spectra of $\mathrm{MB}$ in the presence of (a) $\mathrm{ZnS}$, (b) $\mathrm{Ag}_{2} \mathrm{O}$, and (c) $\mathrm{ZnS} / \mathrm{Ag}_{2} \mathrm{O}$ composite recorded at different time during the photocatalytic tests. 
Figure 7 shows the degradation profiles of $\mathrm{MB}$ at $664 \mathrm{~nm}$ as a function of time. To quantitatively compare the catalytic efficiencies of the above samples, kinetic calculation was carried out. In terms of the Langmuir-Hinshelwood model, degradation can be regarded as a first-order reaction at low $\mathrm{MB}$ concentration. Hence, the fitting calculation of degrading kinetics can be simplified to be linear. Besides, this reaction satisfies the apparent first-order reaction rate equation: $\ln \left(\mathrm{C} / \mathrm{C}_{0}\right)=-k \cdot t$, where $k$ is the apparent rate constant of first-order reaction, and $\ln \left(\mathrm{C} / \mathrm{C}_{0}\right)$ is a function of irradiation time $\mathrm{t}$. Based on this simplified model, relevant fitting results were obtained, as summarized in Figure 7. The calculated $k$ values of $\mathrm{ZnS}$ and $\mathrm{Ag}_{2} \mathrm{O}$ are $0.049 \mathrm{~min}^{-1}$ and $0.024 \mathrm{~min}^{-1}$, respectively, while that of $\mathrm{ZnS} / \mathrm{Ag}_{2} \mathrm{O}$ composite is $0.138 \mathrm{~min}^{-1}$, which is 27.4- and 15.6-times higher than those of $\mathrm{ZnS}$ and $\mathrm{Ag}_{2} \mathrm{O}$. The reaction cannot proceed without a catalyst under UV-Vis irradiation. The results demonstrate that the as-produced $\mathrm{ZnS} / \mathrm{Ag}_{2} \mathrm{O}$ composite has a greatly enhanced photocatalytic activity compared to pristine $\mathrm{ZnS}$ and $\mathrm{Ag}_{2} \mathrm{O}$.
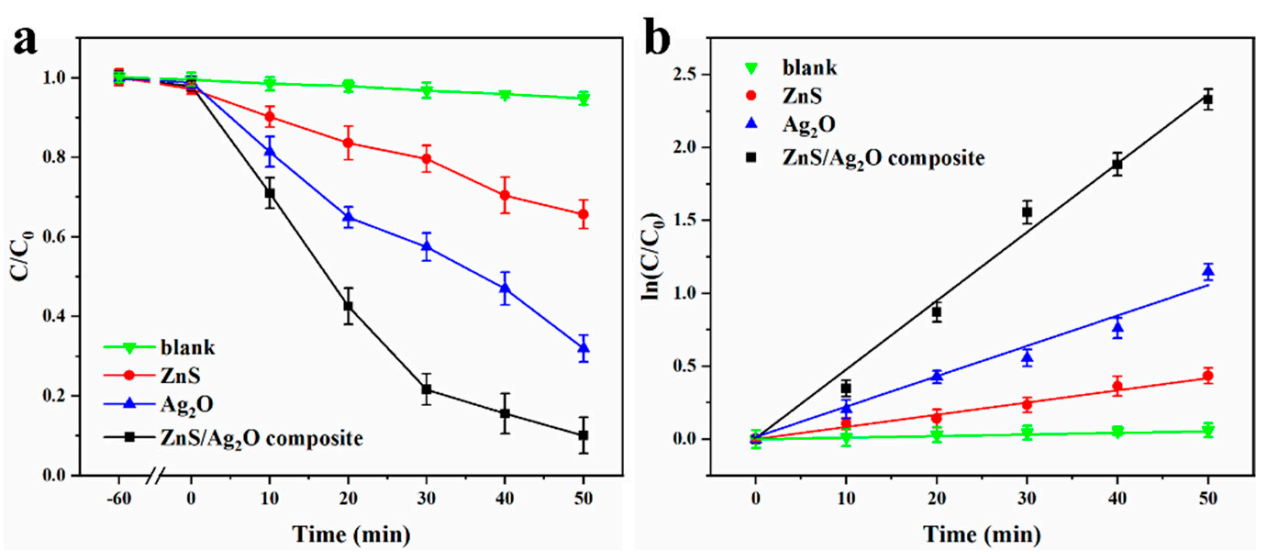

Figure 7. (a) Photocatalytic degradation profiles of MB at $664 \mathrm{~nm}$ as a function of time. (b) Linear fittings of degrading kinetics under different catalytic conditions.

To further evaluate the composite photocatalyst we designed, some relevant reports were retrieved to assess similar catalytic systems for horizontal comparison. All of the selected catalysts used composite photocatalysts with $\mathrm{ZnS}$ as the main body, and the catalytic degradation of $\mathrm{MB}$ was used as the model reaction to investigate the ability to purify organic pollutants in water. Table 1 lists the catalytic activities of some representative ZnS-based photocatalysts with crucial catalytic properties. The rate constant of the catalyst reported in this work is also listed at the bottom of the table to facilitate horizontal comparison. It can be clearly seen that the as-prepared $\mathrm{ZnS} / \mathrm{Ag}_{2} \mathrm{O}$ composite has a high-rate constant among a various of photocatalysts, indicating that it has higher photocatalytic activity than most existing photocatalysts. Therefore, it can be concluded that as-designed $\mathrm{ZnS} / \mathrm{Ag}_{2} \mathrm{O}$ composite is a promising candidate in the field of wastewater purification.

In addition, the recyclability of $\mathrm{ZnS} / \mathrm{Ag}_{2} \mathrm{O}$ composite in $\mathrm{MB}$ degradation reaction under UV-Vis irradiation was studied, as shown in Figure 8. After three successive cycles, the sample retained nearly consistent photocatalytic efficiency without apparent deactivation, indicating that the $\mathrm{ZnS} / \mathrm{Ag}_{2} \mathrm{O}$ composite is stable during the degrading process.

To reveal the photocatalytic mechanism, the main active species in the MB degradation reaction were investigated. Radical scavengers, such as benzoquinone (BQ), ammonium oxalate (AO), tertiary butanol (TBA), and $\mathrm{AgNO}_{3}$, have been used to scavenge superoxide radical anions $\left(\bullet \mathrm{O}^{2-}\right)$, holes $\left(\mathrm{h}^{+}\right)$, electrons $\left(\mathrm{e}^{-}\right)$, or hydroxyl free radicals $(\bullet \mathrm{OH})$ respective $[35,36]$. From Figure 9 , the addition of TBA had no obvious influence on the degradation of $\mathrm{MB}$, implying that $\bullet \mathrm{OH}$ are not the primary active species. When $\mathrm{BQ}$ and $\mathrm{AgNO}_{3}$ were added, the reaction rates were dramatically decelerated, indicating that $\bullet \mathrm{O}^{2-}$ has a crucial role in the photocatalytic process $\left(\mathrm{O}_{2}+\mathrm{e}^{-} \rightarrow \bullet \mathrm{O}_{2}^{-}\right)$. Besides, the addition of $\mathrm{AO}$ also remarkably suppressed the reaction, suggesting that $\mathrm{h}^{+}$is involved in the degradation process. 
Table 1. A series of representative ZnS-based photocatalysts in various structures and corresponding catalytic rate constants in the reaction of degrading $\mathrm{MB}$.

\begin{tabular}{|c|c|c|c|c|}
\hline No. & Catalysts & Structures & Rate Constants ${ }^{1}$ & Ref. \\
\hline 1 & $\mathrm{ZnS} / \mathrm{CdS}$ & core/shell structure & $0.119 \min ^{-1}$ & [2] \\
\hline 2 & $\mathrm{ZnS} / \mathrm{TiO}_{2}$ & nanospheres & $0.110 \mathrm{~min}^{-1}$ & [3] \\
\hline 3 & $\mathrm{ZnS} / \mathrm{ZnO}$ & porous nano-crystal films & $0.041 \min ^{-1}$ & [4] \\
\hline 4 & Ag@AgI/ZnS & microspheres & $0.031 \mathrm{~min}^{-1}$ & [5] \\
\hline 5 & $\mathrm{ZnS} / \mathrm{SnO}_{2}$ & nanospheres & $0.046 \mathrm{~min}^{-1}$ & {$[6]$} \\
\hline 6 & $\mathrm{ZnS} / \mathrm{CuS}$ & supported on reduced graphene oxide & $0.159 \min ^{-1}$ & [7] \\
\hline 7 & $\mathrm{ZnS} / \mathrm{MoS}_{2}$ & layered structures & $0.183 \min ^{-1}$ & [8] \\
\hline 8 & $\mathrm{ZnS}-\mathrm{Fe}_{2} \mathrm{O}_{3}$ & supported on reduced graphene oxide & $0.077 \min ^{-1}$ & [9] \\
\hline 9 & $\mathrm{ZnS}-\mathrm{ZnIn}{ }_{2} \mathrm{~S}_{4}$ & porous hierarchical spherical structure & $0.041 \min ^{-1}$ & [10] \\
\hline 10 & $\mathrm{ZnS} / \mathrm{Ag}_{2} \mathrm{O}$ & broccoli-like microspheres with nanorods & $0.138 \min ^{-1}$ & this work \\
\hline
\end{tabular}

\footnotetext{
${ }^{1}$ The data of rate constants in $\mathrm{s}^{-1}$ were all converted into $\mathrm{min}^{-1}$ for convenience to compare.
}

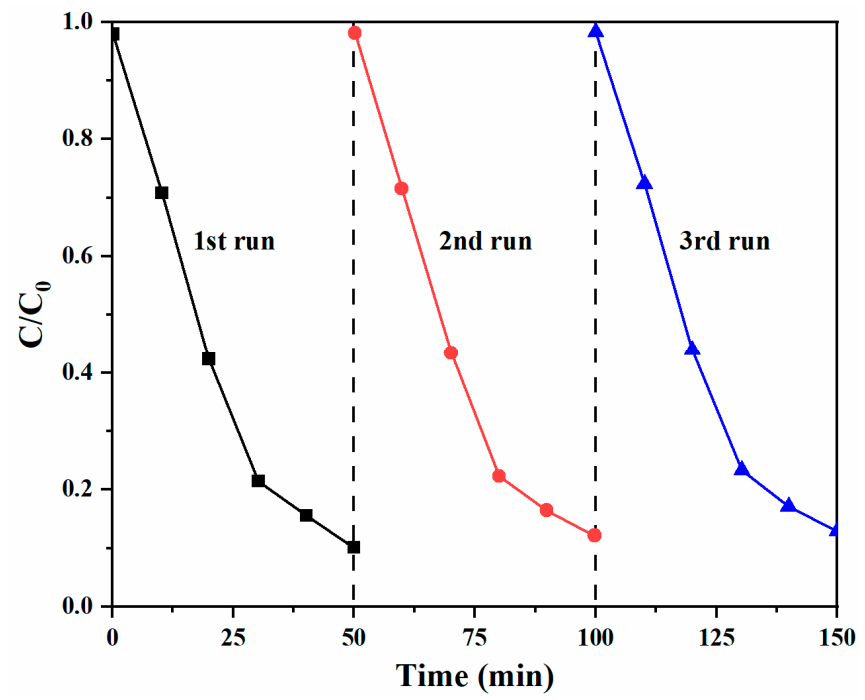

Figure 8. Recycling performance of the $\mathrm{ZnS} / \mathrm{Ag}_{2} \mathrm{O}$ composite for degrading $\mathrm{MB}$.

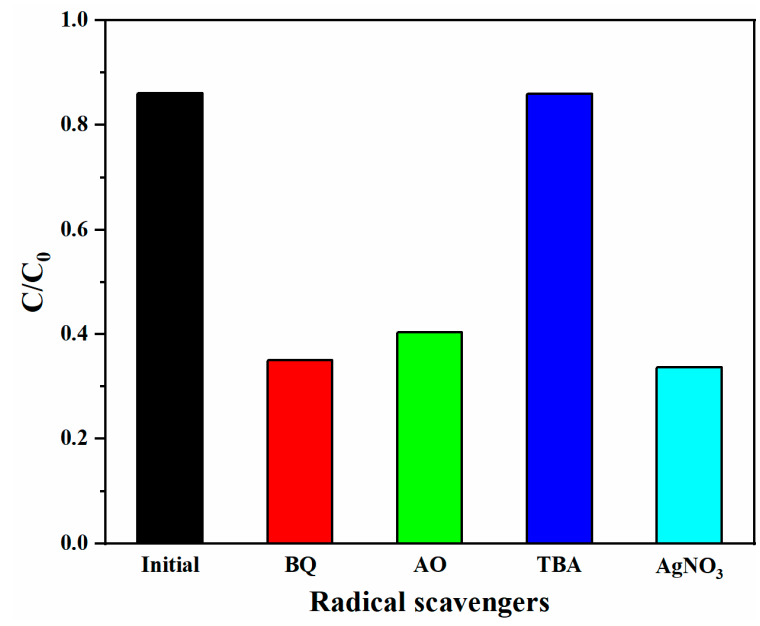

Figure 9. Photocatalytic degradation of $\mathrm{MB}$ by the $\mathrm{ZnS} / \mathrm{Ag}_{2} \mathrm{O}$ composite alone and with different radical scavengers. 
Based on the above results, a possible mechanism for the enhanced photocatalytic activity of $\mathrm{ZnS} / \mathrm{Ag}_{2} \mathrm{O}$ composite was proposed (Figure 10). The activity of a semiconductor photocatalyst mainly depends on the oxidation-reduction potentials of the valence band $(\mathrm{VB})$ and conduction band $(\mathrm{CB})$. Fermi level $\left(\mathrm{E}_{\mathrm{f}}\right.$, dashed line in Figure 10) is the chemical potential of thermodynamic equilibrium. Before n-type semiconductor $\mathrm{ZnS}$ and p-type semiconductor $\mathrm{Ag}_{2} \mathrm{O}$ formed the composite, their Fermi levels had different potentials. When the $\mathrm{ZnS} / \mathrm{Ag}_{2} \mathrm{O}$ composite is formed and irradiated by UV-Vis light, the photogenerated electrons are transferred from $\mathrm{ZnS}$ to $\mathrm{Ag}_{2} \mathrm{O}$ due to the initially higher $\mathrm{CB}$ potential of $\mathrm{ZnS}$ until the quasi-Fermi level (quasi-static equilibrium) is generated [37-40]. This causes the energy bands of $\mathrm{ZnS}$ to shift downward and those of $\mathrm{Ag}_{2} \mathrm{O}$ to shift upward, eventually making the Fermi levels of the two components equal. Because the Fermi level of $\mathrm{ZnS}$ is close to CB but that of $\mathrm{Ag}_{2} \mathrm{O}$ is close to VB [39], the final CB position of $\mathrm{Ag}_{2} \mathrm{O}$ is higher than that of $\mathrm{ZnS}$ [41]. Therefore, the photogenerated electrons transfer from $\mathrm{Ag}_{2} \mathrm{O}$ to $\mathrm{ZnS}$, driven by the potential difference. Then, the photogenerated electrons reduce the surface chemisorbed $\mathrm{O}_{2}$ to form oxidizing species $\bullet \mathrm{O}_{2}{ }^{-}$, which can degrade MB into small molecules [41,42]. Conversely, photogenerated holes on the VB of ZnS can be transferred to $\mathrm{Ag}_{2} \mathrm{O}$, which can be consumed to oxidize $\mathrm{MB}$ directly. In addition, pristine $\mathrm{ZnS}$ has a poor ability for visible-light response due to its high band gap energy. $\mathrm{Ag}_{2} \mathrm{O}$, having a much lower band gap energy, can effectively extend the spectral response range to visual light, elevate the photon efficiency, and improve the activity by forming a composite with $\mathrm{ZnS}$. Therefore, the photocatalytic performance can be greatly enhanced because photogenerated electrons and holes are more efficiently generated and transferred by the $\mathrm{ZnS} / \mathrm{Ag}_{2} \mathrm{O}$ composite.

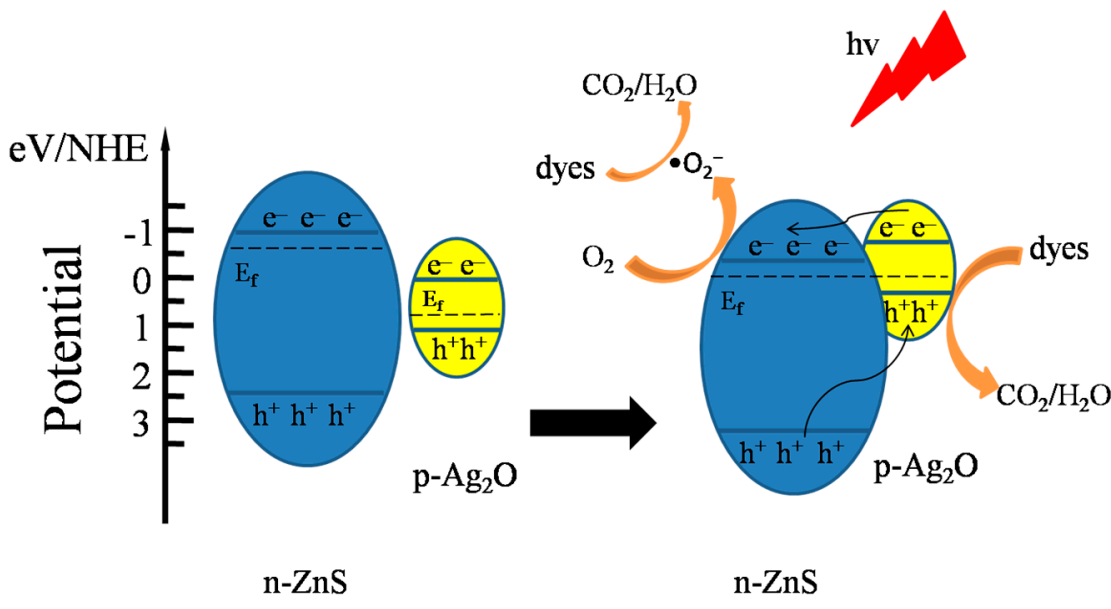

Before Connection

After Connection

Figure 10. Mechanism for the enhanced photocatalytic activity of the $\mathrm{ZnS} / \mathrm{Ag}_{2} \mathrm{O}$ composite.

\section{Conclusions}

In summary, a novel photocatalyst composed of n-type semiconductor ZnS and p-type semiconductor $\mathrm{Ag}_{2} \mathrm{O}$ was designed and constructed by a simple chemical precipitation method. The as-obtained $\mathrm{ZnS} / \mathrm{Ag}_{2} \mathrm{O}$ composite exhibited a high photocatalytic activity and favorable stability among a series of similar ZnS-based composite photocatalysts toward degrading MB. The catalytic rate constant reached up to $0.138 \mathrm{~min}^{-1}$, which is much higher than pristine $\mathrm{ZnS}$ or $\mathrm{Ag}_{2} \mathrm{O}$. Results of catalytic mechanism experiment revealed that the enhanced catalytic activity can be attributed to the efficient separation and transmission of photogenerated carriers and extended light response range brought about by the narrow band gap of $\mathrm{Ag}_{2} \mathrm{O}$. The as-designed $\mathrm{ZnS} / \mathrm{Ag}_{2} \mathrm{O}$ composite is a promising photocatalyst for removing hazardous organics from wastewater due to its high performance. 
Author Contributions: Conceptualization, D.Y., H.F. and H.L.; Data curation, D.Y., H.F., H.L., S.W. and Q.N.; Funding acquisition, H.L.; Investigation, D.Y., P.Q., F.M., P.L. and X.C.; Project administration, H.F., H.L., S.W. and T.L.; Visualization, P.Q., F.M., P.L. and X.C.; Writing - original draft, D.Y. Writing - review \& editing, H.F., H.L. and Q.N. All authors have read and agreed to the published version of the manuscript.

Funding: This research was funded by the National Natural Science Foundation of China, grant number 51402157, and the project of the outstanding scientific research innovation team plan for universities of Shandong province.

Data Availability Statement: Data supporting this study are available within the article.

Conflicts of Interest: The authors declare no conflict of interest.

\section{References}

1. Malik, R.; Tomer, V.K.; Joshi, N.; Dankwort, T.; Lin, L.; Kienle, L. Au-TiO 2 -loaded cubic g- $\mathrm{C}_{3} \mathrm{~N}_{4}$ nanohybrids for photocatalytic and volatile organic amine sensing applications. ACS Appl. Mater. Interfaces 2018, 10, 34087-34097. [CrossRef]

2. Praus, P.; Svoboda, L.; Tokarsk'y, J.; Hospodková, A.; Klemm, V. Core/shell CdS/ZnS nanoparticles: Molecular modelling and characterization by photocatalytic decomposition of Methylene Blue. Appl. Surf. Sci. 2014, 292, 813-822. [CrossRef]

3. Prasannalakshmi, P.; Shanmugam, N. Fabrication of $\mathrm{TiO}_{2} / \mathrm{ZnS}$ nanocomposites for solar energy mediated photocatalytic application. Spectrochim. Acta A 2017, 175, 1-10. [CrossRef]

4. Wang, H.; Liang, L.; Cheng, X.; Luo, Y.; Sun, S. Facile fabrication of porous ZnS and ZnO films by coaxial electrospinning for highly efficient photodegradation of organic dyes. Photochem. Photobiol. 2018, 94, 17-26. [CrossRef]

5. Reddy, D.A.; Choi, J.; Lee, S.; Kim, T.K. Controlled synthesis of heterostructured Ag@AgI/ZnS microspheres with enhanced photocatalytic activity and selective separation of methylene blue from mixture dyes. J. Taiwan Inst. Chem. Eng. 2016, 66, 200-209. [CrossRef]

6. $\mathrm{Hu}, \mathrm{L}$; $\mathrm{Chen}, \mathrm{F} . ; \mathrm{Hu}, \mathrm{P}$; Zou, L.; Hu, X. Hydrothermal synthesis of $\mathrm{SnO}_{2} / \mathrm{ZnS}$ nanocomposite as a photocatalyst for degradation of Rhodamine B under simulated and natural sunlight. J. Mol. Catal. A-Chem. 2016, 411, 203-213. [CrossRef]

7. Yang, L.; Guan, X.; Wang, G.S.; Guan, X.H.; Jia, B. Synthesis of ZnS/CuS nanospheres loaded on reduced graphene oxide as high-performance photocatalysts under simulated sunlight irradiation. New J. Chem. 2017, 41, 5732-5744. [CrossRef]

8. Harish, S.; Prachi; Archana, J.; Navaneethan, M.; Shimomura, M.; Ikeda, H.; Hayakawa, Y. Synergistic interaction of 2D layered $\mathrm{MoS}_{2} / \mathrm{ZnS}$ nanocomposite for highly efficient photocatalytic activity under visible light irradiation. Appl. Surf. Sci. 2019, 488, 36-45. [CrossRef]

9. Liu, Q.; Cao, J.; Ji, Y.; Li, X.; Li, W.; Zhu, Y.; Liu, X.; Li, J.; Yang, J.; Yang, Y. Construction of a direct Z-scheme ZnS quantum dot (QD)- $\mathrm{Fe}_{2} \mathrm{O}_{3}$ QD heterojunction/reduced graphene oxide nanocomposite with enhanced photocatalytic activity. Appl. Surf. Sci. 2020, 506, 144922. [CrossRef]

10. Janani, R.; Melvin, A.A.; Singh, S. Facile one pot in situ synthesis of $\mathrm{ZnS}-\mathrm{ZnIn}_{2} \mathrm{~S}_{4}$ composite for improved photocatalytic applications. Mater. Sci. Semicond. Process 2021, 122, 105480. [CrossRef]

11. Su, Y.; Zhao, X.; Bi, Y.; Han, X. ZnO/Ag- $\mathrm{Ag}_{2} \mathrm{O}$ microstructures for high-performance photocatalytic degradation of organic pollutants. Clean Techn. Environ. Policy 2019, 21, 367-378. [CrossRef]

12. Mohamed, R.M.; Ismail, A.A.; Kadi, M.W.; Alresheedi, A.S.; Mkhalid, I.A. Facile synthesis of mesoporous $\mathrm{Ag}_{2} \mathrm{O}-\mathrm{ZnO}$ heterojunctions for efficient promotion of visible light photodegradation of tetracycline. ACS Omega 2020, 5, 33269-33279. [CrossRef] [PubMed]

13. Chellammal, S.; Sankar, S. Energy gap studies of ZnS nanocrystallites. Mat. Sci. Semicon. Proc. 2010, 13, 214-216. [CrossRef]

14. Raksha, K.R.; Ananda, S.; Madegowda, N.M. Study of kinetics of photocatalysis, bacterial inactivation and OH scavenging activity of electrochemically synthesized Se ${ }^{4+}$ doped ZnS nanoparticles. J. Mol. Catal. A Chem. 2015, 396, 319-327. [CrossRef]

15. Zhang, J.; Yu, J.; Zhang, Y.; Li, Q.; Gong, J.R. Visible light photocatalytic $\mathrm{H}_{2}$-production activity of CuS/ZnS porous nanosheets based on photoinduced interfacial charge transfer. Nano Lett. 2011, 11, 4774-4779. [CrossRef]

16. Singla, S.; Pal, B. Highly porous ZnS microspheres for superior photoactivity after Au and Pt deposition and thermal treatment. Mater. Res. Bull. 2013, 48, 4867-4871. [CrossRef]

17. Peng, Y.; Shang, L.; Cao, Y.; Wang, Q.; Zhao, Y.; Zhou, C.; Bian, T.; Wu, L.Z.; Tung, C.H.; Zhang, T. Effects of surfactants on visible-light-driven photocatalytic hydrogen evolution activities of AgInZn $7 S_{9}$ nanorods. Appl. Surf. Sci. 2015, 358, 485-490. [CrossRef]

18. Wu, Z.D.; Chen, L.L.; Xing, C.S.; Jiang, D.L.; Xie, J.M.; Chen, M. Controlled synthesis of $\mathrm{Bi}_{2} \mathrm{~S}_{3} / \mathrm{ZnS}$ microspheres by an in-situ ion-exchange process with enhanced visible light photocatalytic activity. Dalton Trans. 2013, 42, 12980-12988. [CrossRef]

19. Wu, D.; Jiang, Y.; Yuan, Y.; Wu, J.; Jiang, K. ZnO-ZnS heterostructures with enhanced optical and photocatalytic properties. J. Nanopar. Res. 2011, 13, 2875-2886. [CrossRef]

20. Wang, H.L.; Zhang, L.S.; Chen, Z.G.; Hu, J.Q.; Li, S.J.; Wang, Z.H.; Liu, J.S.; Wang, X.C. Semiconductor heterojunction photocatalysts: Design, construction, and photocatalytic performances. Chem. Soc. Rev. 2014, 43, 5234-5244. [CrossRef] 
21. Qu, Y.Q.; Duan, X.F. Progress, challenge and perspective of heterogeneous photocatalysts. Chem. Soc. Rev. 2013, 42, 2568-2580. [CrossRef] [PubMed]

22. Wang, Q.; Geng, B.Y.; Wang, S.Z. ZnO/Au hybrid nanoarchitectures: Wet-chemical synthesis and structurally enhanced photocatalytic performance. Environ. Sci. Technol. 2009, 43, 8968-8973. [CrossRef] [PubMed]

23. Huang, H.W.; Wang, S.B.; Tian, N.; Zhang, Y.H. Ag- $\mathrm{C}_{3} \mathrm{~N}_{4} / \mathrm{Bi}_{2} \mathrm{O}_{2} \mathrm{CO}_{3}$ composite with high visible-light-driven photocatalytic activity for rhodamine B degradation. RSC Adv. 2014, 4, 5561-5567. [CrossRef]

24. Ida, Y.; Watase, S.; Shinagawa, T.; Watanabe, M.; Chigane, M.; Inaba, M.; Tasaka, A.; Izaki, M. Direct electrodeposition of 1.46 eV bandgap silver (I) oxide semiconductor films by electrogenerated acid. Chem. Mater. 2008, 20, 1254-1256. [CrossRef]

25. Zou, J.; Xu, Y.; Hou, B.; Wu, D.; Sun, Y.H. Self-assembly $\mathrm{Ag}_{2} \mathrm{O}$ nanoparticles into nanowires with the aid of amino-functionalized silica nanoparticles. Powder Technol. 2008, 183, 122-126. [CrossRef]

26. Bugarcic, Z.M.; Divac, V.M.; Gavrilovic, M.P. An efficient route to phenylselenoethers in the presence of Ag 2 O. Monatsh. Chem. 2007, 138, 985-988. [CrossRef]

27. Tian, Q.Y.; Shi, D.X.; Sha, Y.W. $\mathrm{CuO}$ and $\mathrm{Ag}_{2} \mathrm{O} / \mathrm{CuO}$ catalyzed oxidation of aldehydes to the corresponding carboxylic acids by molecular oxygen. Molecules 2008, 13, 948-957. [CrossRef]

28. Lalitha, K.; Reddy, J.K.; Sharma, M.V.P.; Kumari, V.D.; Subrahmanyam, M. Continuous hydrogen production activity over finely dispersed $\mathrm{Ag}_{2} \mathrm{O} / \mathrm{TiO}_{2}$ catalysts from methanol: Water mixtures under solar irradiation: A structure-activity correlation. Int. J. Hydrog. Energy 2010, 35, 3991-4001. [CrossRef]

29. Wang, X.F.; Li, S.F.; Yu, H.G.; Yu, J.G.; Liu, S.W. $\mathrm{Ag}_{2} \mathrm{O}$ as a new visible-light photocatalyst: Self-stability and high photocatalytic activity. Chem. Eur. J. 2011, 17, 7777-7780. [CrossRef]

30. Sarkar, D.; Ghosh, C.K.; Mukherjee, S.; Chattopadhyay, K.K. Three dimensional $\mathrm{Ag}_{2} \mathrm{O} / \mathrm{TiO}_{2}$ type-II (p-n) nanoheterojunctions for superior photocatalytic activity. ACS Appl. Mater. Int. 2013, 5, 331-337. [CrossRef] [PubMed]

31. Ma, S.S.; Xue, J.J.; Zhou, Y.M.; Zhang, Z.W. Photochemical synthesis of $\mathrm{ZnO} / \mathrm{Ag}_{2} \mathrm{O}$ heterostructures with enhanced ultraviolet and visible photocatalytic activity. J. Mater. Chem. A 2014, 2, 7272-7278. [CrossRef]

32. Chen, L.; Hua, H.; Yang, Q.; Hu, C.G. Visible-light photocatalytic activity of $\mathrm{Ag}_{2} \mathrm{O}$ coated $\mathrm{Bi}_{2} \mathrm{WO}_{6}$ hierarchical microspheres assembled by nanosheets. Appl. Surf. Sci. 2015, 327, 62-67. [CrossRef]

33. Ren, H.T.; Jia, S.Y.; Wu, Y.; Wu, S.H.; Zhang, T.H.; Han, X. Improved photochemical reactivities of $\mathrm{Ag}_{2} \mathrm{O} / \mathrm{g}-\mathrm{C}_{3} \mathrm{~N}_{4}$ in phenol degradation under UV and visible light. Ind. Eng. Chem. Res. 2014, 53, 17645-17653. [CrossRef]

34. Mondal, D.K.; Phukan, G.; Paul, N.; Borah, J.P. Improved self heating and optical properties of bifunctional $\mathrm{Fe}_{3} \mathrm{O}_{4} / \mathrm{ZnS}$ nanocomposites for magnetic hyperthermia application. J. Mag. Mag. Mater. 2021, 528, 167809. [CrossRef]

35. Liu, S.Q.; Yang, M.Q.; Xu, Y.J. Surface charge promotes the synthesis of large, flat structured graphene-(CdS nanowire)-TiO 2 nanocomposites as versatile visible light photocatalysts. J. Mater. Chem. A 2014, 2, 430-440. [CrossRef]

36. Qin, N.; Liu, Y.H.; Wu, W.M.; Shen, L.J.; Chen, X.; Li, Z.H.; Wu, L. One-dimensional CdS/ $\mathrm{TiO}_{2}$ nanofibers composites as efficient visible-light-driven photocatalysts for selective organic transformation: Synthesis, characterization and performance. Langmuir 2015, 31, 1203-1209. [CrossRef]

37. Chen, X.B.; Mao, S.S. Titanium dioxide nanomaterials: Synthesis, properties, modifications, and applications. Chem. Rev. 2007, 107, 2891-2959. [CrossRef] [PubMed]

38. Zhang, J.L.; Liu, H.; Ma, Z. Flower-like $\mathrm{Ag}_{2} \mathrm{O} / \mathrm{Bi}_{2} \mathrm{MoO}_{6}$ p-n heterojunction with enhanced photocatalytic activity under visible light irradiation. J. Mol. Catal. A-Chem. 2016, 424, 37-44. [CrossRef]

39. Chang, X.X.; Wang, T.; Zhang, P.; Zhang, J.J.; Li, A.; Gong, J. Enhanced surface reaction kinetics and charge separation of p-n heterojunction $\mathrm{Co}_{3} \mathrm{O}_{4} / \mathrm{BiVO}_{4}$ photoanodes. J. Am. Chem. Soc. 2015, 137, 8356-8359. [CrossRef]

40. Yang, S.B.; Xu, D.B.; Chen, B.Y.; Luo, B.F.; Yan, X.; Xiao, L.S.; Shi, W.D. Synthesis and visible-light-driven photocatalytic activity of p-n heterojunction $\mathrm{Ag}_{2} \mathrm{O} / \mathrm{NaTaO}_{3}$ nanocubes. Appl. Surf. Sci. 2016, 383, 214-221. [CrossRef]

41. Jiang, D.L.; Chen, L.L.; Zhu, J.J.; Chen, M.; Shi, W.D.; Xie, J.M. Novel p-n heterojunction photocatalyst constructed by porous graphite-like $\mathrm{C}_{3} \mathrm{~N}_{4}$ and nanostructured BiOI: Facile synthesis and enhanced photocatalytic activity. Dalton Trans. 2013, 42, 15726-15734. [CrossRef] [PubMed]

42. Chen, Y.; Huang, R.; Chen, D.; Wang, Y.; Liu, W.; Li, X.; Li, Z. Exploring the different photocatalytic performance for dye degradations over hexagonal $\mathrm{ZnIn}_{2} \mathrm{~S}_{4}$ microspheres and cubic $\mathrm{ZnIn}_{2} \mathrm{~S}_{4}$ nanoparticles. ACS Appl. Mater. Inter. 2012, 4, $2273-2279$. [CrossRef] [PubMed] 